\title{
Investigation of The Relationship Between the University Student Wrestlers' Difficulties in Regulating Positive Emotion with Sport- Specific Achievement Motivation
}

\author{
Mehmet Ulukan* \\ School of Management, Aydın Adnan Menderes University, Sports Science Faculty, Aydın, Turkey \\ * E-mail of the corresponding author: mulukan@adu.edu.tr
}

\begin{abstract}
The aim of the research is to examine the relationship between the difficulties in organizing positive emotions and sports-specific success motivation of athletes participating in the inter-university wrestling championship. The sample consisted of 107 athletes. Data collection tools, Weiss et al. (2015) developed by, Asic1 et al. (2018)'s 13items Difficulties in Emotion Regulation Scale Positive (DERS-Positive), Willis (1982)'s developed, Tiryaki and Gödelek (1997)'s adapted to Turkish, 40-item “Sports-Specific Achievement Motivation Scale (SSAMS) was used. Descriptive analysis, t-test, Anova and correlation were applied to the data. The level of significance designated .05 . As a result of the research, wrestlers who compete in the greco-roman category are based on gender; On the whole scale of difficulties in regulating positive emotion, according to gender in wrestlers who is wrestling in the free category; There was a difference in favor of male wrestlers in non-acceptance, goals and impulse subscales. It was observed that there was a difference in the scale and the sub-dimensions of the women and men wrestlers 'Difficulties in Regulating Positive Emotion according to the parents' attitude. It has been observed that there is a difference in the overall and sub-dimensions of the Success Motivation in Sport Scale of women and men wrestlers according to the parents' attitude.

Between the Scale of Difficulties in Regulation Positive Emotion and the Scale of Performance Motivation in Sports as a result of the research; positive among the subdimensions of not accepting, succeeding and avoiding failure in female wrestlers, negative among the sub-dimensions of impulse, success and failure to avoid failure, With the Scale of Difficulties in Regulation Emotion Scale Positive in male wrestlers, a low level of positiveoriented relationship was observed in the sub-dimensions of the Scale of Success motivation in sports, showing strength, success and avoiding failure.
\end{abstract}

Keywords: sport, emotion regulation, success, motivation

DOI: $10.7176 / \mathrm{JEP} / 11-21-24$

Publication date:July 31 st 2020

\section{Introduction}

It is generally accepted that the competitiveness that exists in the nature of the sport is due to the motive of success. The main point of the need for success approach is that some individuals are more satisfied with being successful than others. The perception of success varies from person to person. If the performance-dependent outcome is judged to be one's effort and ability, it can be considered success. But if the performance-related result is judged to be one's incompetence and low effort, it is considered a failure. For this reason, one's success can be seen as a failure by others (Tiryaki and Gödelek, 1997).

Motivation is defined as the various internal and external factors that drive the organism to behavior, determine the regularity and continuity of these behaviors, give direction and purpose to behavior, and the mechanisms that enable their functioning (Aydin 2001). The goals that people are trying to accomplish can be instrumental to their later goals. In this respect, most goals, such as trust, position, wealth, which are considered as the reason for human attitudes and behaviors, are in fact nothing more than a goal in realizing the ultimate goal of any individual, that is, "being himself". (Terzioğlu, 1990)

Motivation has two important characteristics. The first is that motivation is a person-specific situation. One element that motivates any person may not motivate another person. In other words, motivational factors can vary from person to person. The expectation of earning more money can motivate one person, while the expectation of promoting another can motivate another. The second characteristic of motivation is that the motivation process can only be observed in human movements. Whether the person is motivated or not is inferred from their behavior. Therefore, it can be said that the inner mood of the motivated person is reflected in their behavior (Koçel, 2005). 
Motivation for success occurs as a result of an excess of expectations in the goals of the athlete. The pleasure and satisfaction felt from having accomplished a job encourages and engenders new aspirations, for future achievements (Dirmen, 2014). Athletes show determination to win and achieve. Motivation for success has been expressed as the athlete's resistance to failure, struggling to achieve the targeted task, and uncertain situations (Cox,1990). Athletes who focus on success are mindful of their duties and responsibilities and strive to do well. (Can and Kaçay, 2016; Gill, 1986).

The motivation for success has been defined as doing a job skillfully, accomplishing it perfectly, overcoming obstacles, doing it better than others (Gill, 1986). The strength of the athletes to participate in high intensity training and to keep it going for a long time can be explained by the "success motivation theory", which has an important place among motivation theories. This theory explains why individuals participate in a physical activity, why they expend so much power to achieve what is difficult, and why they continue to do so for so long (Tiryaki, 2000).

There is a considerable correlation between motivation and success in the formation of performance. One of the main objectives of an athlete is to perform the highest performance in training and competition. So, the higher the motivation levels of the athletes, the more likely the performance will increase. Therefore, it is emphasized in both competitions and scientific studies that the technical and tactical development of athletes as well as achieving success is achieved with high motivation. Athletes, coaches, training scientists, sports psychologists and other individuals and organizations that are closely involved in sports always strive to be successful in sports. Competitions are often organized where the high performance of the athletes is demonstrated. (Çam, 1990).

Emotion regulation is "a concept that covers all internal and external processes for experiencing, evaluating and changing intense and temporary emotional responses in order to reach the goal of the individual" (Thompson, 1994, p. 25). Editing emotion; (a) recognizing and understanding emotions, (b) accepting emotions, (c) being able to control impulsive behavior while experiencing negative emotions and acting in line with desired goals, and (d) being flexible in using situationally appropriate emotion regulation strategies to change emotional responses includes abilities (Gratz and Roemer, 2004).

Emotions are complex systems that develop throughout the evolutionary history of man, preparing the organism against environmental stimuli and challenges (Keltner \& Gross, 1999). Like emotions, moods can be either positive or negative, but mood is less common than emotions; people are relatively aware of their emotions, but less aware of their emotions. However, the differences between a prolonged emotion and mood can be subtle, and it is difficult to explain the difference of a prolonged sadness (emotion) from depressive mood (Platin, 2015).

Emotion regulation occurs in the form of reducing or increasing positive and negative emotions through various strategies. Emotion regulation involves reducing or stopping emotions when one's emotion results from misjudging an event and produces behavioral responses that are not of long-term benefit or make it difficult for their emotional response to achieve their important goals. Because a person's mind is elsewhere, the emotional lives of deprivation give reactions, emotional responses to appropriate someone else's good news, one emotion to another in cases you want to replace it with emotion, emotion regulation, emotion start or increase includes (Gross, 1999a,b).

By its most general definition, emotion regulation can be defined as changing one's emotions according to environmental requirements. Successful emotion editing process is generally defined as the capacity to organize in such a way that one is aware of one's emotions, makes sense of their feelings, accepts them, and is able to maintain a state of well-being in the face of emotions that force him or her (Gratz and Roemer, 2004).

The main function of emotion regulation is satisfying hedonic needs, facilitating specific goals and tasks, and maximizing personality functions (Koole, 2009). Being successful in regulating emotion does not mean having the ability to escape negative emotional experiences or to quickly reduce negative emotional experiences. Being successful in emotion regulation means being able to function effectively when faced with experiences that produce intense emotional responses (Pollock et al., 2016).

Motivated by the success of athletes, as in the international arena to represent their country in difficulties in regulation positive emotion in emotion regulation in determining the goals of the wrestlers to identify the factors which affect the impulse to accept adjust levels and negative emotions will be guiding. For this reason, it is important to establish the relationship between the difficulties experienced in organizing positive emotions and the concepts of success motivation specific to sports and it is thought that it will contribute to sports science. In addition, the study of the capacity to organize positive emotions, which is indicative of the ability to look at events differently, may have an important effect in shaping the teams that will be assigned to individual athletes in the future in the field of Wrestling, where tactical-technical battles take place. The lack of research conducted in the related field article increases the importance of the study. Based on this basic knowledge, the research's problem is "Is there a relationship between regulation positive emotion and sport-specific motivation for achievement?"it 
is designated as. For this purpose, answers to the following sub-problems have been sought:

1. What is the level of success motivation specific to sports with the difficulty experienced by the athletes in the positive emotion arrangement?

2. Is there a significant difference between the difficulty in organizing positive emotions according to the gender and categories of athletes?

3. Is there a significant difference between the motivation of sports-specific success by gender and categories of athletes?

4. Is there a meaningful relationship between the difficulty experienced by the athletes in the positive emotion regulation and the motivation for achievement specific to the sport?

\section{Methodology}

\subsection{Research Goal}

The aim of the research is to examine the relationship between difficulties in regulating positive emotions and sports-specific achievement motivation in the universities wrestling championship.

\subsection{Sample and Data Collection}

The model of the study is the relational scanning model used to describe the relationship between two or more variables.

The study group participated in the 2019-2020 academic year in Turkey intercollegiate wrestling championships, 30 women, 77 men consisted of a total of 107 athletes. Since the universe is limited to a certain region, simple random sampling technique was used in sample selection.

(DERS- Postive) and Willis (1982) developed by Tiryaki and Gödelek (1997), adapted to Turkish, 40-item sportsspecific achievement motivation scale (SSAMS) was used.

In order to measure the motivation of sport-specific achievement, a 40-item Sports-Specific Achievement Motivation Scale (SSAMS) developed by Willis (1982) and adapted to Turkish by Tiryaki and Gödelek (1997) was used. The Sport-Specific Achievement Motivation Scale, which was adapted to Turkish athletes by Tiryaki and Gödelek, consists of a total of 40 items and the items are five-point likert type, which are expressed as "never", "very little", "sometimes", "very much" and "always". The scale was shown to be measured by 12 items to show strength, 17 to succeed, and 11 to avoid failure (Tiryaki et al., 1997). Three different types of scores can be obtained from scale to Sport-Specific Achievement Motivation total score, "Showing Strength", "Approach to Success" and "Avoiding Failure" sub-dimension. The high scores indicate that the Sport-Specific Achievement Motivation is high. In order to measure the Difficulties in Emotion Regulation Scale Positive in the study, a scale of 13-item positive emotions (DERS-Positive) was developed by Weiss, Gratz and Lavender (2015) and adapted to Turkish by (Asıc1 et al. 2018). A rating between 5-5 [1-almost never (0-10\%), 5-almost always (91-100\%)] from participants on a 5-point Likert type scale how valid each item on the scale is for them. They are asked to evaluate. The high scores obtained from the scale indicate that the difficulties in regulating positive emotions have increased. It was determined that the Difficulties in Emotion Regulating Scale Positive (DERS-Positive) consists of three subscales explaining $60.26 \%$ of the total variance. These subscales were named as having difficulty in accepting positive emotions (not being accepted), difficulty in engaging with goal-oriented behaviors while experiencing positive emotions (goals), and difficulty in controlling their impulsive behaviors while experiencing positive emotions.

\subsection{Analyzing of Data}

The data obtained in the study were examined in the SPSS.25 program. Descriptive statistics were used in the analysis of the data, $t$ test for independent groups in binary group comparisons, one-way analysis of variance in comparing multiple groups, ANOVA, Correlation test was used to examine the relationship between Difficulties in Emotion Positive Regulation and Sport-Specific Achievement Motivation. In the interpretation of the results .05 significance level was used. 


\section{Findings / Results}

In the study, whether university student wrestlers ' DERS-Positive and SSAMS scores vary by gender t-test analysis Table of the results of the analyzed analysis.1. is also given.

Table 1. T-test results of DERS-Positive and SSAMS scores of university student wrestlers by gender

\begin{tabular}{|c|c|c|c|c|c|c|c|}
\hline Dimensions & Categories & Gender & $\mathbf{n}$ & $\overline{\mathbf{x}}$ & SD & $\mathbf{t}$ & $\mathbf{p}$ \\
\hline \multirow{4}{*}{ DERS-Positive } & \multirow{2}{*}{ Greco-roman } & Female & 5 & 2,51 & ,46 & \multirow{2}{*}{$-2,700$} & \multirow{2}{*}{, $035^{*}$} \\
\hline & & Male & 34 & 3,13 &, 59 & & \\
\hline & \multirow{2}{*}{ Freestyle } & Female & 25 & 2,69 & ,53 & \multirow{2}{*}{,- 981} & \multirow{2}{*}{,331 } \\
\hline & & Male & 43 & 2,82 &, 57 & & \\
\hline \multirow{4}{*}{ Recjection } & \multirow{2}{*}{ Greco-roman } & Female & 5 & 3,50 & 1,17 & \multirow{2}{*}{1,099} & \multirow{2}{*}{, 324} \\
\hline & & Male & 34 & 2,89 & ,94 & & \\
\hline & \multirow{2}{*}{ Freestyle } & Female & 25 & 2,70 & ,80 & \multirow{2}{*}{$-2,021$} & \multirow{2}{*}{,048* } \\
\hline & & Male & 43 & 3,14 & ,96 & & \\
\hline \multirow{4}{*}{ Targets } & \multirow{2}{*}{ Greco-roman } & Female & 5 & 3,60 & 1,04 & \multirow{2}{*}{,- 529} & \multirow{2}{*}{,619 } \\
\hline & & Male & 34 & 3,86 & ,93 & & \\
\hline & \multirow{2}{*}{ Freestyle } & Female & 25 & 3,47 & 1,06 & \multirow{2}{*}{$-2,530$} & \multirow{2}{*}{,016* } \\
\hline & & Male & 43 & 4,08 &, 74 & & \\
\hline \multirow{4}{*}{ Impulse } & \multirow{2}{*}{ Greco-roman } & Female & 5 & 3,64 & 1,04 & \multirow{2}{*}{,- 477} & \multirow{2}{*}{, 653} \\
\hline & & Male & 34 & 3,88 & ,97 & & \\
\hline & \multirow{2}{*}{ Freestyle } & Female & 25 & 3,61 & 1,03 & \multirow{2}{*}{$-2,112$} & \multirow{2}{*}{, $042 *$} \\
\hline & & Male & 43 & 4,09 &, 67 & & \\
\hline \multirow{4}{*}{ SSAMS } & Greco-roman & Female & 5 & 3,34 & 1,11 & 678 & 531 \\
\hline & ureco-roman & Male & 34 & 3,69 &, 69 &,$- 0 / 0$ & (501 \\
\hline & Freectule & Female & 25 & 3,05 &, 87 & 1448 & 154 \\
\hline & Freestyle & Male & 43 & 3,37 &, 89 & $-1,448$ &, 154 \\
\hline & Greco-roman & Female & 5 & 3,27 & 1,11 & & 478 \\
\hline Showing Power & ureco-roman & Male & 34 & 3,66 &, 80 &,$- / 1 / 2$ &, $4 / 8$ \\
\hline & & Female & 25 & 3,16 &, 87 & & 231 \\
\hline & Freestyle & Male & 43 & 3,43 & ,93 &,- 1211 &, 231 \\
\hline & & Female & 5 & 3,41 & 1,20 & & \\
\hline Being Successful & Greco-roman & Male & 34 & 3,75 &, 73 &,- 621 & 565 \\
\hline being successiu & Freestyle & Female & 25 & 3,05 &, 88 & -1309 & 196 \\
\hline & Freestyle & Male & 43 & 3,34 &, 87 & $-1,309$ &, 190 \\
\hline & Greco-roman & Female & 5 & 3,31 & ,99 & -636 & 555 \\
\hline Avoiding Failure & ureco-roman & Male & 34 & 3,60 &, 72 &,- 036 & ד5 \\
\hline Avolaing Faliure & Freestyle & Female & 25 & 3,92 & ,96 & -1717 & 097 \\
\hline & rieestyre & Male & 43 & 3,34 & ,99 & $-1, / 11$ & ,092 \\
\hline
\end{tabular}

When Table. 1 is examined, according to the dimension of difficulties in organizing positive emotions; It was observed that there was a significant difference between the mean scores of wrestlers fighting in the Greco-Roman category $(\mathrm{t}=-2,700 \mathrm{p}=, 035) \mathrm{p}<.05$ in favor of male wrestlers, and there was no significant difference between the average scores of wrestlers fighting in the free category. In the refusal sub-dimension; It was observed that there was no significant difference between the mean scores of wrestlers fighting in the Greco-Roman category according to gender, and there was a difference in favor of male wrestlers among the wrestlers in the free category $(t=-2,021 p=, 048)$. In the lower dimension of non-acceptance; there is no significant difference between the points averages of the wrestlers fighting in the grecoromian category by gender, and the points averages of the wrestlers fighting in the free Category $(\mathrm{t}=-2,021 \mathrm{p}=, 048) \mathrm{p}<.05$ the level of significance was seen to be the difference in favour of male wrestlers. In the lower dimension of the goals; there is no significant difference between the points averages of the wrestlers fighting in the Greco-Roman category and the points averages of the wrestlers fighting in the freestyle category $(t=-2.530 \mathrm{p}=.016) \mathrm{p}<.05$ the level of significance was seen to be the 
difference in favour of male wrestlers. In the lower dimension of impulse, there is no significant difference between the points averages of wrestlers fighting in the Greco-Roman category by gender, and between the points averages of wrestlers fighting in the freestyle category $(t=-2.530 \mathrm{p}=.016) \mathrm{p}<.05$ the level of significance was seen to be the difference in favour of male wrestlers. In sport-specific success motivation and sub-dimensions; It was observed that there is no difference between the average scores of wrestlers who struggle in the Greco-Roman and free category according to gender.

In the research, whether the university student wrestlers' DERS-Positive and SSAMS scores change according to their participation in social life, t-test analysis was analyzed and the results of the analysis were analyzed. Table.2. are also given.

Table 2. T-Test Analysis Results of University Student Wrestlers' DERS-Positive and SSAMS Scores According to Social Participation Status

\begin{tabular}{|c|c|c|c|c|c|c|c|}
\hline Dimensions & Categories & $\begin{array}{l}\text { Participating } \\
\text { in Social Life }\end{array}$ & $\mathrm{n}$ & & SD & $\mathrm{t}$ & $\mathrm{p}$ \\
\hline \multirow{4}{*}{ DERS-Positive } & \multirow{2}{*}{ Greco-roman } & Yes & 23 & 2,95 & ,65 & \multirow{2}{*}{$-1,220$} & \multirow{2}{*}{,212 } \\
\hline & & No & 16 & 3,19 &, 52 & & \\
\hline & \multirow{2}{*}{ Freestyle } & Yes & 35 & 2,60 & ,52 & \multirow{2}{*}{$-2,742$} & \multirow{2}{*}{, $008 *$} \\
\hline & & No & 33 & 2,95 &, 55 & & \\
\hline \multirow{4}{*}{ Non-acceptance } & \multirow{2}{*}{ Greco-roman } & Yes & 23 & 2,82 & ,96 & \multirow{2}{*}{$-1,217$} & \multirow{2}{*}{,233 } \\
\hline & & No & 16 & 3,20 & ,99 & & \\
\hline & \multirow{2}{*}{ Freestyle } & Yes & 35 & 2,58 & ,82 & \multirow{2}{*}{$-4,070$} & \multirow{2}{*}{, $000 *$} \\
\hline & & No & 33 & 3,40 &, 85 & & \\
\hline \multirow{4}{*}{ Targets } & \multirow{2}{*}{ Greco-roman } & Yes & 23 & 3,85 &, 87 & \multirow[b]{2}{*}{,160 } & \multirow[b]{2}{*}{874} \\
\hline & & No & 16 & 3,80 & 1,05 & & \\
\hline & \multirow{2}{*}{ Freestyle } & Yes & 35 & 3,74 & ,99 & \multirow{2}{*}{$-1,029$} & \multirow{2}{*}{,307 } \\
\hline & & No & 33 & 3,97 &, 82 & & \\
\hline \multirow{4}{*}{ Impulse } & \multirow{2}{*}{ Greco-roman } & Yes & 23 & 3,91 & ,96 & \multirow{2}{*}{,508 } & \multirow{2}{*}{,615 } \\
\hline & & No & 16 & 3,75 & 1,01 & & \\
\hline & \multirow{2}{*}{ Freestyle } & Yes & 35 & 3,82 & 91 & \multirow{2}{*}{,- 919} & \multirow{2}{*}{,361 } \\
\hline & & No & 33 & 4,01 &, 77 & & \\
\hline \multirow{4}{*}{ SSAMS } & Greco-roman & Yes & 23 & 3,41 &, 82 & -2651 & $012 *$ \\
\hline & Uieco-romant & No & 16 & 3,97 &, 47 & $-2,001$ &, $012^{\circ}$ \\
\hline & & Yes & 35 & 3,07 & 87 & & \\
\hline & Freestyle & No & 33 & 3,44 &, 88 & $-1,780$ & , 080 \\
\hline & Greco-roman & Yes & 23 & 3,36 & 94 & & \\
\hline Showing Power & Greco-roman & No & 16 & 3,98 &, 50 & $-2,667$ &, $012^{*}$ \\
\hline snowing rower & Freestvle & Yes & 35 & 3,13 &, 88 & 1877 & 065 \\
\hline & Freestyle & No & 33 & 3,54 & ,90 & $-1,8 / 1$ & , \\
\hline & Grocoromon & Yes & 23 & 3,48 &, 88 & & \\
\hline Beino Successful & Greco-roman & No & 16 & 4,04 &, 48 & 68 &, $015^{*}$ \\
\hline Being successiul & & Yes & 35 & 3,05 &, 85 & 1780 & 070 \\
\hline & Freestyle & No & 33 & 3,43 &, 88 & 89 &, $0 / 8$ \\
\hline & Greco-roman & Yes & 23 & 3,38 &, 81 & -2081 & $044 *$ \\
\hline Avoidino Failure & oneco-roman & No & 16 & 3,84 &, 57 & $-2,001$ &, $044^{\prime}$ \\
\hline Avolaing railure & Freestyle & Yes & 35 & 3,02 & ,98 & -1445 & 153 \\
\hline & rreestyle & No & 33 & 3,36 & ,99 & $-1,443$ & , 153 \\
\hline
\end{tabular}

When Table. 2 is examined, according to the scale of difficulties in organizing positive emotions; There is no significant difference between the average scores of wrestlers who fight in the Greco-Roman category according to participation in social life, and between the average scores of the wrestlers who fight in the free category $(t=-$ $2,742, p=, 008) p<, 05$ is significant in favor of those with low participation in social life. there was a difference. According to the non-acceptance sub-dimension; There is no significant difference between the average scores of wrestlers fighting in the Greco-Roman category according to their participation in social life, whereas the difference between the mean scores of wrestlers fighting in the free category $(t=-4,070 \mathrm{p}=, 000)$ in favor of those with low participation in social life is significant. It was observed. According to the goals and impulse sub- 
dimensions; There was no significant difference between the mean scores of wrestlers, who are categorized as Greco-Roman and free-standing, according to participation in social life. According to the sport-specific success motivation dimension; There is a significant difference between wrestlers struggling in the Greco-Roman category according to their participation in social life $(t=-2,651 \mathrm{p}=, 012) \mathrm{p}<, 05$ in the level of significance in favor of those with low participation in social life, and there is a significant difference between the average scores of wrestlers fighting in the free category. It was not observed. According to the sub-dimension of showing power; There is a significant difference between wrestlers struggling in the Greco-Roman category according to their participation in social life $(\mathrm{t}=-2,667 \mathrm{p}=, 012) \mathrm{p}<, 05$ in the level of significance in favor of those with low participation in social life, whereas there is a significant difference between the average scores of wrestlers fighting in the free category. It was not observed. According to the sub-dimension of being successful; There is a significant difference between wrestlers struggling in the Greco-Roman category according to their participation in social life $(t=-2,568 p=, 015)$ in favor of those with low participation in social life at the level of significance of $p<$. It was not observed. According to the sub-dimension of failure avoidance, there is a significant difference between wrestlers who struggle in the Greco-Roman category according to their participation in social life $(\mathrm{t}=-2,081 \mathrm{p}=$, 044) $\mathrm{p}<, 05$ in the level of significance in favor of those with low participation in social life. There was no significant difference between.

In the study, whether or not the university student wrestlers' DERS-Positive and SSAMS scores change according to their mother attitude, the results of the analysis analyzed by anova analysis are given in Table.3.

Table 3 Anova Analysis Results according to The Mother Attitude of University Student Wrestlers' DERSPositive and SSAMS Scores

\begin{tabular}{|c|c|c|c|c|c|c|c|}
\hline Dimensions & Gender & Attitudes & $\mathrm{n}$ & & SD & $\mathrm{F}$ & $\mathrm{p}$ \\
\hline \multirow{6}{*}{ DERS-Positive } & \multirow{3}{*}{ Female } & Extreme realease & 10 & 2,89 &, 530 & & \\
\hline & & Normal & 7 & 2,24 & ,218 & \multirow{2}{*}{4,106} & \multirow{2}{*}{, $028^{*}$} \\
\hline & & Overprotective & 13 & 2,70 &, 506 & & \\
\hline & \multirow{3}{*}{ Male } & Extreme realease & 27 & 2,98 & ,665 & & \\
\hline & & Normal & 21 & 3,00 &, 543 & \multirow{2}{*}{, 167} & \multirow{2}{*}{,874 } \\
\hline & & Overprotective & 29 & 2,91 &, 580 & & \\
\hline \multirow{6}{*}{ Non-acceptance } & \multirow{3}{*}{ Female } & Extreme realease & 10 & 2,85 & 1,062 & & \\
\hline & & Normal & 7 & 2,82 & ,910 & \multirow{2}{*}{,002 } & \multirow{2}{*}{,998 } \\
\hline & & Overprotective & 13 & 2,83 &, 844 & & \\
\hline & \multirow{3}{*}{ Male } & Extreme realease & 27 & 2,81 & ,898 & & \\
\hline & & Normal & 21 & 3,30 &, 816 & \multirow{2}{*}{1,534} & \multirow{2}{*}{,222 } \\
\hline & & Overprotective & 29 & 3,04 & 1,073 & & \\
\hline \multirow{6}{*}{ Targets } & & Extreme realease & 10 & 3,40 & ,966 & & \\
\hline & Female & Normal & 7 & 3,57 & 1,143 & \multirow{2}{*}{, 060} & \multirow{2}{*}{, 942} \\
\hline & & Overprotective & 13 & 3,52 & 1,111 & & \\
\hline & \multirow{3}{*}{ Male } & Extreme realease & 27 & 4,31 &, 369 & & \\
\hline & & Normal & 21 & 3,77 & ,981 & \multirow{2}{*}{3,428} & \multirow{2}{*}{, $038^{*}$} \\
\hline & & Overprotective & 29 & 3,83 & ,945 & & \\
\hline \multirow{6}{*}{ Impulse } & & Extreme realease & 10 & 3,56 & 1,010 & & \\
\hline & Female & Normal & 7 & 3,63 & 1,048 & \multirow{2}{*}{, 020} & \multirow{2}{*}{,980 } \\
\hline & & Overprotective & 13 & 3,65 & 1,074 & & \\
\hline & \multirow{3}{*}{ Male } & Extreme realease & 27 & 4,34 &, 375 & & \\
\hline & & Normal & 21 & 3,67 & 1,040 & \multirow{2}{*}{4,625} & \multirow{2}{*}{, $013^{*}$} \\
\hline & & Overprotective & 29 & 3,92 & ,846 & & \\
\hline
\end{tabular}




\begin{tabular}{|c|c|c|c|c|c|c|c|}
\hline \multirow{6}{*}{ SSAMS } & \multirow{3}{*}{ Female } & Extreme realease & 10 & 3,39 & ,862 & & \\
\hline & & Normal & 7 & 3,64 &, 806 & \multirow{2}{*}{5,146} & \multirow{2}{*}{, $013^{*}$} \\
\hline & & Overprotective & 13 & 2,57 & ,730 & & \\
\hline & \multirow{3}{*}{ Male } & Extreme realease & 27 & 3,77 & ,678 & \multirow{3}{*}{6,744} & \\
\hline & & Normal & 21 & 3,74 & ,695 & & \multirow{2}{*}{, $002 *$} \\
\hline & & Overprotective & 29 & 3,10 & ,872 & & \\
\hline \multirow{6}{*}{ Showing Power } & \multirow{3}{*}{ Female } & Extreme realease & 10 & 3,38 & ,896 & & \\
\hline & & Normal & 7 & 3,74 &, 711 & \multirow{2}{*}{4,148} & \multirow{2}{*}{, $027^{*}$} \\
\hline & & Overprotective & 13 & 2,71 & ,789 & & \\
\hline & \multirow{3}{*}{ Male } & Extreme realease & 27 & 3,75 & ,685 & & \\
\hline & & Normal & 21 & 3,75 &, 832 & \multirow{2}{*}{4,104} & \multirow{2}{*}{, $020 *$} \\
\hline & & Overprotective & 29 & 3,18 & ,975 & & \\
\hline \multirow{6}{*}{ Being Successful } & \multirow{3}{*}{ Female } & Extreme realease & 10 & 3,41 & ,894 & & \\
\hline & & Normal & 7 & 3,64 & ,905 & \multirow{2}{*}{4,550} & \multirow{2}{*}{, $020^{*}$} \\
\hline & & Overprotective & 13 & 2,60 & ,739 & & \\
\hline & \multirow{3}{*}{ Male } & Extreme realease & 27 & 3,83 & ,697 & & \\
\hline & & Normal & 21 & 3,75 &, 725 & \multirow{2}{*}{8,252} & \multirow{2}{*}{, $001^{*}$} \\
\hline & & Overprotective & 29 & 3,07 & ,842 & & \\
\hline \multirow{6}{*}{ Avoiding Failure } & \multirow{3}{*}{ Female } & Extreme realease & 10 & 3,37 &, 873 & & \\
\hline & & Normal & 7 & 3,53 & ,899 & \multirow{2}{*}{5,905} & \multirow{2}{*}{, $007^{*}$} \\
\hline & & Overprotective & 13 & 2,98 & ,212 & & \\
\hline & \multirow{3}{*}{ Male } & Extreme realease & 27 & 3,69 & ,715 & & \\
\hline & & Normal & 21 & 3,71 & ,768 & \multirow{2}{*}{5,486} & \multirow{2}{*}{, $006^{*}$} \\
\hline & & Overprotective & 29 & 3,05 & ,974 & & \\
\hline
\end{tabular}

When Table. 3 is examined, female wrestlers' scores on the level of difficulty in regulation positive emotion are significantly different between the average score at the level of $\mathrm{p}=.028, \mathrm{p} .05$, according to the mother's attitude, the difference was found to be between the score of wrestlers (2.89) with an excessively free attitude and the scores of wrestlers with normal attitudes (2.24). Male wrestlers' maternal attitude scores were not a significant difference between scores. In the refusal sub-dimension; According to the mother attitude of the male and male wrestlers, there was no significant difference between the mean scores. In the goals sub-dimension; There is no difference between the mean scores of female wrestlers according to the mother's attitude, and there is a difference between the mean scores of the male wrestlers' mother attitude in the level of $\mathrm{p}=, 038, \mathrm{p}<, 05$, and this difference is also over-free attitude score (4.31) and normal attitude score. (3.77) was found to be. The lower size of the impulse; Female wrestlers have no difference between the average score according to the maternal attitude, and male wrestlers have a significant difference in the level of $p=.013, p<.05$, and this difference is between excessive free attitude behavior score (4.34) and normal attitude behavior score (3.67).

Sports-specific success motivation scale scores; According to the maternal attitude of female wrestlers, the average score was found to be between $\mathrm{p}=.013, \mathrm{p}<.05$ level, which is aware that there is an over-free attitude score (3.64) and normal attitude score (2.57). According to the maternal attitudes of male wrestlers, there is a significant difference at the level of $p=, 002, p<, 05$, and this difference is the mean score of those who have an overprotective attitude (3.77) and those who have an overly free mother $(3,10)$ It was seen to be among the averages. Depending on the level of significance of the power display subsize; According to the maternal attitude of female wrestlers, there was a significant difference between $\mathrm{p}=.027, \mathrm{p}<.05$, which was between excessive free attitude score (3.75) and overprotective attitude behavior score (3.18). Male wrestlers' maternal attitude is among the points averages $\mathrm{p}=.020, \mathrm{p}<.05$ level significant difference, this difference was found to be between the average score (3.73) and the scores of those with over-free attitudes (2.89). In the sub-dimension of being successful; There is a significant difference between the mean scores of women wrestlers with maternal attitude at the level of $p=, 020, p<, 05$, 
and this difference is the average of the ones with overprotective attitude (3.60) and the average of those with extreme free attitude (3.41). It was observed that between. There is a significant difference between the mean scores of male wrestlers according to the mother's attitude at the level of $p=001, p<, 05$, and this difference is between the scores of the ones with excessive free attitude (3.84) and those of the ones with excessive protective attitude (3.07). It has been observed. In the sub-dimension of not avoiding failure; It was observed that there was a significant difference between the mean scores of female wrestlers according to the mother's attitude at the level of $p=007, p<, 05$, and this difference was between the scores of those with a normal attitude (3.53) and those with an overprotective attitude (2.98). Among the average points according to the maternal attitude of male wrestlers, there was a significant difference in the level of $\mathrm{p}=.006, \mathrm{p}<, 05$, and the proportion of those with normal attitudes (3.71) and scores of those with overprotective attitudes (3.05).

In the study, whether the university student wrestlers' DERS-Positive and SSAMS scores change according to their father's attitude, the results of the analysis analyzed by anova analysis are shown in Table.4. are also given.

Table 4. Anova Analysis Results according to The Father Attitude of University Student Wrestlers' DERSPositive and SSAMS Scores

\begin{tabular}{|c|c|c|c|c|c|c|c|}
\hline Dimensions & Gender & Attitudes & $\mathrm{n}$ & & $\mathrm{SD}$ & $\mathrm{F}$ & $\mathrm{p}$ \\
\hline \multirow{6}{*}{ DERS-Positive } & \multirow{3}{*}{ Female } & Extreme realease & 12 & 2,68 &, 572 & \multirow{3}{*}{4,392} & \multirow{3}{*}{, $022^{*}$} \\
\hline & & Normal & 8 & 2,28 & ,271 & & \\
\hline & & Overprotective & 10 & 2,93 & ,432 & & \\
\hline & \multirow{3}{*}{ Male } & Extreme realease & 17 & 2,61 &, 559 & \multirow{3}{*}{4,753} & \multirow{3}{*}{, $011 *$} \\
\hline & & Normal & 31 & 2,97 &, 577 & & \\
\hline & & Overprotective & 29 & 3,15 &, 564 & & \\
\hline \multirow{6}{*}{ Non-acceptance } & \multirow{3}{*}{ Female } & Extreme realease & 12 & 3,33 & ,907 & \multirow{3}{*}{3,629} & \multirow{3}{*}{, $040^{*}$} \\
\hline & & Normal & 8 & 2,53 &, 828 & & \\
\hline & & Overprotective & 10 & 2,47 &, 731 & & \\
\hline & \multirow{3}{*}{ Male } & Extreme realease & 17 & 3,22 & ,956 & \multirow{3}{*}{1,135} & \multirow{3}{*}{, 327} \\
\hline & & Normal & 31 & 3,12 & 987 & & \\
\hline & & Overprotective & 29 & 2,83 & ,914 & & \\
\hline \multirow{6}{*}{ Targets } & \multirow{3}{*}{ Female } & Extreme realease & 12 & 3,52 & 1,002 & \multirow{3}{*}{, 067} & \multirow{3}{*}{,936 } \\
\hline & & Normal & 8 & 3,37 & 1,044 & & \\
\hline & & Overprotective & 10 & 3,55 & 1,171 & & \\
\hline & \multirow{3}{*}{ Male } & Extreme realease & 17 & 3,88 &, 801 & \multirow{3}{*}{, 452} & \multirow{3}{*}{638} \\
\hline & & Normal & 31 & 3,93 &, 859 & & \\
\hline & & Overprotective & 29 & 4,09 &, 828 & & \\
\hline & & Extreme realease & 12 & 3,63 & ,987 & & \\
\hline & Female & Normal & 8 & 3,80 & 1,064 & & \\
\hline Imnulse & & Overprotective & 10 & 3,44 & 1,078 &, 271 &, 765 \\
\hline Impulse & & Extreme realease & 17 & 4,01 &, 817 & & \\
\hline & Male & Normal & 31 & 3,94 &, 862 & & \\
\hline & & Overprotective & 29 & 4,06 &, 798 & 160 &, 853 \\
\hline & & Extreme realease & 12 & 3,70 &, 854 & & \\
\hline & Female & Normal & 8 & 2,57 &, 620 & 6460 & $005 *$ \\
\hline SSAMS & & Overprotective & 10 & 2,78 &, 757 & 6,460 &, $005^{*}$ \\
\hline SSAMS & & Extreme realease & 17 & 2,87 &, 845 & & \\
\hline & Male & Normal & 31 & 3,69 & ,704 & & \\
\hline & & Overprotective & 29 & 3,69 &, 744 & 7,899 &, $001 *$ \\
\hline & & Extreme realease & 12 & 3,73 &, 806 & & \\
\hline & Female & Normal & 8 & 2,74 &, 806 & & \\
\hline Showing Power & & Overprotective & 10 & 2,86 &, 767 & 4,937 &, $015^{*}$ \\
\hline Showing Power & & Extreme realease & 17 & 2,89 &, 879 & & \\
\hline & Male & Normal & 31 & 3,73 &, 762 & 6816 & กกา* \\
\hline & & Overprotective & 29 & 3,70 &, 837 & 6,816 &, $002^{*}$ \\
\hline & & Extreme realease & 12 & 3,75 & ,893 & & \\
\hline & Female & Normal & 8 & 2,55 &, 535 & & \\
\hline Dain $\mathrm{C}$ no & & Overprotective & 10 & 2,79 &, 739 & 6,871 &, $004^{*}$ \\
\hline Being Successful & & Extreme realease & 17 & 2,91 &, 827 & & \\
\hline & Male & Normal & 31 & 3,67 &, 734 & & \\
\hline & & Overprotective & 29 & 3,73 &, 784 & 6,904 &, $002 *$ \\
\hline & & Extreme realease & 12 & 3,61 & ,937 & & \\
\hline & Female & Normal & 8 & 2,43 & ,709 & & \\
\hline & & Overprotective & 10 & 2,68 &, 796 & 5,717 &, $009^{*}$ \\
\hline Avoiding Failure & & Extreme realease & 17 & 2,78 &, 867 & & \\
\hline & Male & Normal & 31 & 3,68 &, 814 & & \\
\hline & & Overprotective & 29 & 3,61 &, 789 & 7,513 &, $001 *$ \\
\hline
\end{tabular}


When Table. 4 is examined, there is a significant difference between female wrestlers' mean scores at the level of $\mathrm{p}=, 022, \mathrm{p}<, 05$ according to the father's attitude regarding the difficulties in organizing positive emotions, the scores of those who have an overprotective father (2.93) and normal attitude scores (2.28) was found to be. There is a significant difference between the mean scores of male wrestlers according to the father's attitude at the level of $\mathrm{p}=, 011, \mathrm{p}<, 05$, and this difference is the scores of those with an overprotective attitude (3.15) and the scores of those with an overly free attitude (2.61). It was observed that between. In the refusal sub-dimension; According to fathers' attitudes of female wrestlers, there was a significant difference at the level of $p=, 040, p<, 05$, and this difference was between the scores of those whose father had an excessively free attitude (3.33) and those who had an overprotective attitude (2.47). According to the father attitude of male wrestlers, there was no significant difference between the mean scores. In the goals sub-dimension and the impulse sub-dimension; According to the father attitude of male and male wrestlers, there was no significant difference between the mean scores.

It was observed that there was a significant difference between the scores of female wrestlers according to the paternal attitude regarding the motivation of success specific to the sport at the level of $p=, 005, p<, 05$, between the scores of those with paternal extreme freestyle (3.70) and the scores of those with normal attitude (2.57). According to the father's attitude, there was a significant difference between the points of male wrestlers at the level of $\mathrm{p}=.001, \mathrm{p}<, 05$, and the scores of those with overprotective attitudes (3.69) and scores (2.87) of those with over-free attitudes. In the sub-dimension of showing power; According to fathers' attitudes of female wrestlers, there was a significant difference at the level of $p=, 015, p<, 05$, and it was found that those who had an excessive attitude towards this awareness (3.73) and those with normal attitude (2.74). The scores of male wrestlers according to paternal attitude were found to be significantly different at the level of $p=, 002, p<, 05$, between the scores of those with normal father attitude (3.73) and the scores of those with free attitude (2.89). In the sub-dimension of being successful; There was a significant difference between the scores of female wrestlers according to the father's attitude at the level of $\mathrm{p}=, 004, \mathrm{p}<, 05$, and this difference was between the scores of those with an overprotective attitude (3.73) and those with an overly free attitude (2.91). Male wrestlers ' scores according to paternal attitude were significantly different at $p=, 002, p<, 05$ level, this difference was found to be between the scores of those with normal paternal attitude (3.73) and the values of free attitude behavior (2.89). In the sub-dimension of not avoiding failure; It was observed that there was a significant difference between the scores of female wrestlers according to the father's attitude at the level of $p=009, p<, 05$, and this difference was between the scores of those with excessive attitude (3.61) and those with normal attitude (2.43). Male wrestlers ' scores according to paternal attitude were significantly different at $\mathrm{p}=, 001, \mathrm{p}<, 05$ level, this difference was found to be between the scores of those with normal paternal attitude (3.68) and those with free attitude (2.78).

In the research, the relationship between DERS-Positive scores of female and male wrestlers of university students and SSAMS scores was analyzed by simple correlation analysis. are also given.

Table 5. University Student Male Wrestlers' DERS-Positive and SSAMS Scores simple Correlation Analysis Results

\begin{tabular}{|c|c|c|c|c|c|c|}
\hline Variables & Gender & & $\begin{array}{l}\text { DERS- } \\
\text { Positive }\end{array}$ & Non-acceptance & Targets & Impulse \\
\hline \multirow{4}{*}{ SSAMS } & \multirow{2}{*}{ Female } & $\mathrm{r}$ &, 175 & ,248 &,- 146 &,- 237 \\
\hline & & $\mathrm{p}$ & ,355 & , 187 & ,443 & ,208 \\
\hline & \multirow{2}{*}{ Male } & $\mathrm{r}$ &, $259 *$ & , 106 &,- 023 &,- 072 \\
\hline & & $\mathrm{p}$ & ,023 & ,359 & ,841 &, 534 \\
\hline \multirow{4}{*}{ Showing Power } & \multirow{2}{*}{ Female } & $\mathrm{r}$ & ,205* & , 186 &,- 098 &,- 149 \\
\hline & & $\mathrm{p}$ & ,207 & ,325 &, 605 &, 432 \\
\hline & \multirow{2}{*}{ Male } & $\mathrm{r}$ & ,228* & , 169 &,- 072 &,- 080 \\
\hline & & $\mathrm{p}$ &, 046 &, 141 & ,532 & ,488 \\
\hline \multirow{4}{*}{ Being Successful } & \multirow{2}{*}{ Female } & $\mathrm{r}$ & , 142 & ,254 &,- 161 &,- 256 \\
\hline & & $\mathrm{p}$ & ,455 &, 175 & ,396 &, 173 \\
\hline & \multirow{2}{*}{ Male } & $\mathrm{r}$ &, $265 *$ & ,082 & 010 &,- 042 \\
\hline & & $\mathrm{p}$ &, 020 & ,476 & ,928 &, 718 \\
\hline \multirow{4}{*}{ Avoiding Failure } & \multirow{2}{*}{ Female } & $\mathrm{r}$ &, 175 & 275 &,- 156 &,- 273 \\
\hline & & $\mathrm{p}$ & ,354 & ,141 & ,412 &, 145 \\
\hline & \multirow{2}{*}{ Male } & $\mathrm{r}$ &, $235 *$ &, 053 &,- 017 &,- 097 \\
\hline & & $\mathrm{p}$ &, 039 & ,644 & ,883 & ,400 \\
\hline
\end{tabular}


In the study, the correlation score of the variables and their sub-dimensions was evaluated in the opposite direction due to the situation specific to the assessment used for determining the difficulties experienced in organizing positive emotions. Namely; The high scores obtained in regulating positive emotion mean that the level of difficulty experienced increased. Therefore, Table 5 where the data is presented. Although there was a linear increase between the positive emotion regulation score and the motivation score in sports, the correlation score was interpreted to express the reverse relationship. Table in this frame 5 when examined, it was observed that there was a low level of positive correlation between the score average of male wrestlers on the scale of difficulties in organizing positive emotions and the score average of the sports-specific success motivation scale ( $\mathrm{r}=, 259, \mathrm{p}=$, 023) $\mathrm{p}<, 05$ level of significance. However, contrary to what is expected in the research, it can be interpreted that male wrestlers experience difficulties in positive emotion, while the increase in value shows that men experience difficulties in emotion regulation, and sports specific motivation scores increase.

Among the average scores of the male wrestlers' difficulties in organizing positive emotions and the strength of the sports-specific success motivation scale; $(r=, 228, p=, 046) p<, 05$ significance level was found to be a low level of positive correlation. However, contrary to what is expected in the research, although the difficulties experienced in organizing positive emotions in male wrestlers increased, the mean scores of showing strength from the sub-dimensions of sport-specific motivation for success also increased. Although the difficulties in regulating positive emotions have increased in female wrestlers, it can be interpreted that the scores of the sub-dimension showing strength from the sub-dimensions of motivation for sports are also increasing.

It was observed that there was a positive low-level correlation between the difficulties experienced in organizing positive emotions of male wrestlers and the sub-dimensions of success-specific success motivation sub-dimension $(\mathrm{r}=, 265, \mathrm{p}=, 020) \mathrm{p}<.05$. However, contrary to what is expected in the research, although the difficulties in organizing positive emotions in male wrestlers increase, it can be interpreted that the scores of the sub-dimension of success, which are among the motivation subspecies of sport-specific motivation, have also increased. However, contrary to what is expected in the research, although the difficulties in organizing positive emotions in male wrestlers increase, it can be interpreted that the scores of the sub-dimension of success, which are among the motivation subspecies of sport-specific motivation, have also increased.

\section{Result and Discussion}

In this study, 30 women and 77 men, a total of 107 wrestlers in the wrestling teams of universities were examined in terms of sport-specific success motivation and difficulties in organizing positive emotions, various personal variables and the relationship between the two variables was tried to be explained.

In the research, it was observed that female wrestlers were more successful than male wrestlers, according to the overall scale of difficulties in organizing positive emotions, and the mean scores of the goals and impulse subscales. However, it was observed that this was not a factor that lowered the motivation of male wrestlers in sports. Indeed, motivation in sport between the average achievement scores showed no difference between male and female wrestlers. In addition, it is another finding that female wrestlers struggling in the Greco-Roman category have a higher average than female wrestlers fighting in the free category. This result is thought to be due to the competition rules of the Greco-Roman category being more difficult than the free category and therefore less preferred by female wrestlers. From the perspective of gender patterns, it can be said that female wrestlers have a higher average score in feeling positive and organizing positive emotions even if they are struggling in the category of GrecoRoman, which can be considered as a male-dominated sub-branch. In addition, it is considered that female wrestlers who are athletes in the newly developing female wrestling branch see themselves as successful, and male athletes motivate themselves successfully due to long and intensive training, so there is no significant difference between the mean scores of gender and categories. In the findings obtained from Er et al. (2003) " Analysis of Success Motivation in Sport in Terms of Gender ", it is reported that the motivation to show strength (POW) is higher in women. A significant difference was found in the statistical results of Aktaş et al. (2006) regarding basketball players' motivation approach to success (MAS). According to the results; men's motivation to approach success (MAS) scores were lower than women's scores. Kayhan (2017) examined the relationship between aggression and emotional dysfunction in adolescents. The research sample consists of 216 high school students. According to the findings, it was found that there is a difference between sexes in terms of physical aggression and verbal aggression; It was observed that there was a positive relationship between aggression and emotional difficulty.

Yaman et al (2001) that they have done "Investigation of Success Motivation Differences Between Competitive Volleyball, Handball Players and Women in the Turkish 1st leagues" according to the theme study's findings, 
women of strength to show motive handball are higher, the motive to approach success aversion high and failure in women footballers it is determined that the motivation is high among female volleyball players and female soccer players. The results obtained from these studies on similar topics support the research results of the gender and gender wrestlers of the study we conducted. When the wrestlers' positive emotion regulation scale and subdimensions according to their participation in social life were examined, it was observed that wrestlers who struggle in both free and Greco-Roman categories with higher participation in social life had a higher average score. As a matter of fact, there was a significant difference in terms of their participation in social life between the average scores of wrestlers who struggled in the free category in the whole scale and in the non-acceptance sub-dimension. Contrary to what is expected in the research, it is observed that the wrestlers with lower participation in social life have higher motivation in terms of motivation and sub-dimensions in sports. A significant difference was found between the mean scores of the wrestlers who struggled in the Greco-Roman category in all and all sub-dimensions of the scale in terms of their participation in social life. It is thought that this result is due to the fact that an intense training process is not able to allocate time to social life due to the fact that wrestling is an individual sport and all responsibility for success and performance is in the athlete.

In his study, Altan (2006) examined at the effect of the socialization behavior of the mother and the personality traits of the child on the emotion regulation skills of the child. In this study, emotion regulation ability was found to be the predictor of the interaction between positive parent behaviors and child's reactive personality traits and warm personality traits. The results obtained from these studies on similar subjects support the research results in terms of gender and social participation level of female and male wrestlers according to the categories of our study.

When the statistical results of basketball players' motivation to avoid failure (MAF) are examined in the studies of Aktaş et al. (2006), it is seen that there is no significant difference in the results. In Erman et al. (2004), no significant difference was found in the sub-parameters of success motivation between male and female athletes in their studies on comparing sports-specific success motivations of athletes and men. The results of these studies on similar subjects do not coincide with the findings we obtained in terms of participation of both male and female wrestlers in terms of gender and social life.

In the study, it was observed that female wrestlers with a mother's normal attitude were higher in the scale of difficulties in organizing positive emotions, and that there was a significant difference between the other groups. In the goals and impulse sub-dimensions, it was observed that the average score of male wrestlers whose mothers had normal attitude was higher and there was a significant difference between other groups. It was observed that the difference was significant with other groups in which the female athletes with normal attitude were higher in the overall sport motivation scale and in all of its sub-dimensions. In male wrestlers, wrestlers with excessive free mother attitudes were found to be higher in the sub-dimensions of showing strength and success in the whole scale. In the sub-dimension of not avoiding failure, it was observed that the average score of male wrestlers with a normal attitude was higher.

In the study, it was observed that the average of female wrestlers with a father's normal attitude and male wrestlers with a father's extreme free attitude were higher in the scale of difficulties in organizing positive emotions, and there was a significant difference between other groups. In the non-acceptance sub-dimension, it was observed that the mean scores of female and male wrestlers whose father had an overprotective attitude were higher and there was a significant difference between other groups. It was observed that the difference was significant with the other groups where the average score of female wrestlers whose father was extremely free attitude was higher in all of the sub-dimensions of the sport-specific success motivation scale. In male wrestlers, the average score of male wrestlers with a father's extreme free attitude was lower in the whole scale; wrestlers with normal father attitude in the sub-dimensions of showing strength and success were found to have higher average scores. In the sub-dimension of not avoiding failure, it was observed that the average score of male wrestlers with a normal attitude was higher. When these results are evaluated, it is thought that the individuals grown up in the family with excessive attitude have matured early due to the fact that they have to develop earlier in organizing their own life and that they have become more self-sufficient both in organizing positive emotions and motivation for success in sports.

Aka (2011) looked at the relationship between emotion recognition, perceived parental attitudes, emotion regulation and psychological health in adolescents and adults. According to the results of the study, a significant relationship was found between adolescents' seeing their parents warm and sincere and their cognitive emotion regulation skills. People who are young and who perceive their parents warmly use the cognitive rearrangement strategy more than those who are older and those who perceive their parents less warm. Tekin (2017) examined the effect of adolescents' perceived parental attitudes on creativity levels and emotion regulation processes. According to the research, emotional difficulties of adolescents differ in the impulse sub-dimension according to 
the age variable, they differ in the non-acceptance and openness sub-dimensions according to the gender variable, and there is a significant difference in the impulse sub-dimension according to the parental education level and maternal employment status variable. The results obtained from these studies on similar subjects support the results we obtained in terms of both mother attitude and father attitude behaviors of wrestlers according to gender. In the study of Artan (2019), examining the relationship between emotion regulation difficulties and personality traits in university students, it was observed that there was no significant relationship between the sub-dimensions of emotion regulation difficulty scale and parental attitudes. This result shows that the attitude of the mother and father we obtained in our study does not match the results.

According to the results of the research, it was observed that there was a low positive correlation between the average score of the difficulties in organizing positive emotions of male wrestlers and the average of motivation scale for sports-specific success motivation scale. However, contrary to what is expected in the research, although the increase in the value experienced in male wrestlers in organizing positive emotions shows that men experience difficulties in emotion regulation, sports specific motivations of success have also increased.

It has been observed that there is a positive low-level relationship between male wrestlers' difficulties in organizing positive emotions, and the sub-dimensions of showing strength, success and not failure from the sport-specific success motivation scale sub-dimensions. However, contrary to what is expected in the research, despite the increase in the difficulties in organizing positive emotions in male wrestlers, it shows that men have difficulties in emotion regulation, but the sport-specific success motivation scale increases in sub-dimensions of showing strength, being successful and not avoiding failure.

It was observed that there was a positive low-level correlation between female wrestlers' non-acceptance scale of difficulties in regulating positive emotion and the sub-dimension of sport-specific success motivation, success subdimension and failure to avoid failure. However, contrary to what is expected in the research, despite the increase in the difficulties in regulating the sense of not accepting the scale of the difficulties in organizing positive emotions in female wrestlers, it shows that the motivation dimension specific to the sport, the dimensions of being successful and not avoiding failure also increased.

Aslan and Kuru (2002), in their work, 1. They found a positive relationship between league players' motivation to avoid failure and their sportive experience and a negative low significance level between the motives of their $2 \mathrm{nd}$ league players and their sportive experiences. The results obtained from these studies on similar subjects support the low meaningful and positive results of the relationship between the difficulties and sub-dimensions of male wrestlers, who are the results of our study, and sports-specific success motivation and sub-dimensions.

According to the findings obtained from Aktop and Erman's (2002) "Comparison of Team and Individual Athletes' Success Motivation, Self-Esteem and Continuous Anxiety Levels"; It was determined that there is no difference between the athletes engaged in team and individual sports in terms of strength, motivation, and motivation levels of failure, which is a relatively continuous and sport-specific success motivation. The results of this study do not coincide with the low level meaningful and positive results of the relationship between the male wrestlers' difficulties in organizing positive emotions and their sub-dimensions, and the motivation and sub-dimensions of sport-specific success. According to the results obtained, we can say that women can perform in the wrestling branch, which is a performance and combat sport, which requires a high level of motivation, emotion control and skill, without discriminating gender.

\section{Suggestions}

The differences and relationships between emotion levels and motivations of athletes in different sports can be examined. Team athletes and individual athletes can be compared. It can also be examined in terms of different variables.

\section{References}

Aka, B. T. (2011). Percieved Parenting Styles, Emotion Recognition, and Emotion Regulation In Relation To Psychological Well-Being: Symptoms Of Depression, Obssesive-Compulsive Disorder, And Social Anxiety. Doctoral Thesis. Middle East Technical University Institute of Social Sciences. Ankara.

Aktaş, Z., Çobanoğlu, G., Yazıcılar, İ., Er, N. (2006), “Comparison of Sport-Specific Achievement Motivation Level in Terms of Gender in Professional Basketball Players" Journal of Spormeter Physical Education and Sports Sciences, IV (2) 55- 59 
Aktop, A., Erman, K. A. (2002), "Comparison of Team and Individual Athletes Achievement Motivation, SelfEsteem and Trait Anxiety Levels", 7th International Sport Sciences Congress Booklet, Antalya 27-29 October.

Altan, Ö. (2006). The effects of maternal socialization and temperament on children's emotion regulation (Unpublished master thesis). Koç University, İstanbul.

Altunbaş, G. (2014). The effect of psychoeducation program on university students' use of cognitive emotion regulation strategies and perfectionist cognitions. Doctoral Thesis. Gazi University Institute of Educational Sciences. Ankara.

Artan, B. (2019). Examining the Relationship between Emotional Difficulty and Personality Traits of University Students, Master Thesis, Nişantaşı University, Institute of Social Sciences, Istanbul, 22-71.

Asıcı, E., İkiz, F.E., \& Karaca, R. (2018). Difficulties in emotion regulating scale positive (DERS-Positive): Turkish adaptation, validity and reliability study. Kastamonu Education Journal, 26 (5), 1589-1600. doi: 10.24106 / kefdergi.2165

Aslan, A. and Kuru, E (2002). Differences of Achievement Motivation of Professional and Amateur Football Players and Their Relationship with Sports Experience.

Aydın, İ., (2001) Development and Learning Psychology. Istanbul: Alpha Printing

Can, Y., Kaçay, Z. (2016). 'Examining the relationship between athlete identity perception and feelings of courage and self-confidence' Journal of Human Sciences, 13 (3), 6176-6184. doi: 10.14687 / jhs.v13i3.4353

Carl, J. R., Soskin, D. P., Kerns, C., and Barlow, D. H. (2013). Positive emotion regulation in emotional disorders: a theoretical review. Clinical Psychology Review, 33 (3), 343-360. doi: 10.1016 / j.cpr.2013.01.003

Conway, A. M. (2005) Girls, Aggression, And Emotion Regulation. American Journal Of Orthopsychiatry, 75 (2), 334-339

Cox, R. (1990). Sport Psychology, Concepts and Applications, Second Edition, Wm, C. Brown Publishers.

Cüceloğlu, D., Human and Behavior, Remzi Bookstore, Istanbul 1996.

Çam, İ. (1990), Motivation as a Case in Sport and Effects of Motivation on Sporty Performance, D.E. Health Bil. Inst. Body Training and Sports Division. Unpublished Master's Thesis, p: 33-48, Izmir.

Dirmen, A. (2014). Comparison of Successful Motivation Levels of Women Football Team Players Playing in Different Leagues, Master Thesis, Marmara University, Institute of Health Sciences, Istanbul.

Er, N., Çobanoğlu, G., Er, G., Zekioğlu, A., Yazıcılar, İ. (2003), “Analysis of Success Motivation in Sport in Terms of Gender", Poster Paper Presented at the Congress of Physical Education and Sport Social Areas, 10 October 11.

Erman, A.K., Şahan, A. and CAN, S. (2004), Comparison of Sport-Specific Success Motivations of Athletes and Men, 10th ICHPER Sd EuropeanCongress \& TSSA 8th International Sport Science Congress, 1720 November, Antalya.

Gill, DL., (1986) Psychological Dynamics of Sport, Champaign: IL, Human Kinetics

Gratz, K.L. and Roemer, L. (2004). Multidimensional assessment of emotion regulation and dysregulation: Development, factor structure, and initial validation of the difficulties in emotion regulation scale. Journal of Psychopathology and Behavioral Assessment, 26, 41-54.

Gross, J. J. (1999). Emotion regulation: Past, present, future. Cognition \& Emotion, 13 (5), 551-573.

Karasar, N. (2015). Scientific Research Method Nobel Academic Publishing, 28th Edition.

Kayhan, H. (2017). Examining the relationship between aggression and emotion regulation difficulties in adolescence. Master Thesis. Maltepe University Institute of Social Sciences, İstanbul.

Keltner, D., \& Gross, J.J. (1999). Functional accounts of emotions. Cognition and Emotion, 13, 575-599

Koçel T. (2005). Business Management. Istanbul: Beta Publishing.

Koole, S. L. (2009). The psychology of emotion regulation: an integrative review. Cognition and Emotion, 23 (1), 4-41. doi: 10.1080 / 02699930802619031

Manning, N. N. (2010). Convergence and divergence of attachment and emotion regulation during adolescence. Doctoral Thesis, University Of Virginia, Virginia.

Plantin, C. (2015). Emotion and Affect. The International Encyclopedia of Language and Social Interaction, 17 (4) $1-11$. 
Pollock, N. C., McCabe, G. A., Southard, A. C., and Zeigler-Hill, V. (2016). Pathological personality traits and emotion regulation difficul-ties. Personality and Individual Differences, 95, 168-177. doi: 10.1016/j. paid.2016.02.049

Tekin, N. (2016). Investigation of the Effect of Education Program for Supporting the Emotional Development of Children Applied to Mothers in Managing the Emotions of the Mothers and Coping with the Negative Emotions of the Children Unpublished (Doctoral dissertation, Master Thesis. Ankara: Gazi University).

Terzioğlu, A. E. (1990). Concept of Motivation in Sports Education; Journal of Sports Sciences. Volume 2; Marmara University Atatürk Education Faculty Tekel Packaging Plant; Istanbul.

Tiryaki, Ş., Gödelek E. (1997), Adaptation Study of Sports Specific Success Motivation Scale for Turkish Athletes, I. International Sport Psychology Symposium Proceeding Booklet, Bağırgan Publishing House, p: 128-141, Ankara.

Tiryaki, Ş., (2000). Sports Psychology, Theories and Practice. Mersin: Eylül Book and Publishing House

Thompson, R.A. (1994). Emotion regulation: A theme in search of definition. Monographs Of The Society For Research In Child Development, 59 (23), 25-52.

Weiss, N. H., Gratz, K. L., ve Lavender, J. M. (2015). Factor structure and initial validation of a multidimensional measure of difficulties in the regulation of positive emotions the DERS-Positive. Behavior Modification, 39(3), 431-453. doi: 10.1177/0145445514566504.

Yazgan İ. B., Bilgin, M. and Kılıç A., M. (2012). Developmental psychology: Child and adolescent development Ankara: Pegem Academy.

Yaman, M. Duman, S., Hergüner, G. (2001), "Turkey 1 contestant volleyball in the league, Investigation of handball and football Sex Between Success Motivation Differences", Journal of Educational Research, Vol 25, pp 102-107. 